\title{
Protection of neonatal rat cardiac myocytes against radiation-induced damage with agonists of growth hormone-releasing hormone
}

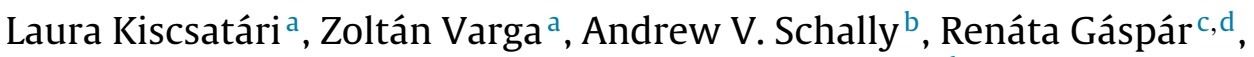 \\ Csilla Terézia Nagy ${ }^{\mathrm{e}}$, Zoltán Giricz $^{\mathrm{e}}$, Péter Ferdinandy ${ }^{\mathrm{d}, \mathrm{e}}$, Gabriella Fábián ${ }^{\mathrm{a}}$, \\ Zsuzsanna Kahán ${ }^{\mathrm{a}, 1}$, Anikó Görbe (MD PhD) ${ }^{\mathrm{c}, \mathrm{d}, \mathrm{e}, *, 1}$ \\ a Department of Oncotherapy, University of Szeged, Szeged, Hungary \\ ${ }^{\mathrm{b}}$ Veterans Affairs Medical Center, Miami FL, USA and Departments of Pathology and Medicine, Divisions of Hematology/Oncology, University of Miami \\ Miller School of Medicine, Miami, FL, USA \\ ${ }^{\mathrm{c}}$ Cardiovascular Research Group, Department of Biochemistry, University of Szeged, Szeged, Hungary \\ d Pharmahungary Group, Szeged, Hungary \\ e Department of Pharmacology and Pharmacotherapy, Semmelweis University, Budapest, Hungary
}

\section{A R T I C L E I N F O}

\section{Article history:}

Received 12 January 2016

Received in revised form 5 July 2016

Accepted 25 July 2016

Available online 30 July 2016

\section{Keywords:}

Cardiac myocytes

Cardioprotection

GHRH agonists

GHRH/SV1 receptors

Radiation damage

\begin{abstract}
A B S T R A C T
Despite the great clinical significance of radiation-induced cardiac damage, experimental investigation of its mechanisms is an unmet need in medicine. Beneficial effects of growth hormone-releasing hormone (GHRH) agonists in regeneration of the heart have been demonstrated. The aim of this study was the evaluation of the potential of modern GHRH agonistic analogs in prevention of radiation damage in an in vitro cardiac myocyte-based model.

Cultures of cardiac myocytes isolated from newborn rats (NRVM) were exposed to a radiation dose of $10 \mathrm{~Gy}$. The effects of the agonistic analogs, JI-34 and MR-356, of human GHRH on cell viability, proliferation, their mechanism of action and the protein expression of the GHRH/SV1 receptors were studied.

JI-34 and MR-356, had no effect on cell viability or proliferation in unirradiated cultures. However, in irradiated cells JI-34 showed protective effects on cell viability at concentrations of 10 and $100 \mathrm{nM}$, and MR-356 at $500 \mathrm{nM}$; but no such protective effect was detected on cell proliferation. Both agonistic analogs decreased radiation-induced ROS level and JI-34 interfered with the activation of SAFE/RISK pathways. Using Western blot analysis, a $52 \mathrm{kDa}$ protein isoform of GHRHR was detected in the samples in both irradiated and unirradiated cells.

Since GHRH agonistic analogs, JI-34 and MR-356 alleviated radiation-induced damage of cardiac myocytes, they should be tested in vivo as potential protective agents against radiogenic heart damage.
\end{abstract}

(c) 2016 Elsevier Ltd. All rights reserved.

\section{Introduction}

Radiation-induced heart diseases including ischemic heart disease, congestive heart failure, electrical conduct defects and valve abnormalities are typically late consequences of radiotherapy, occurring many years or decades after treatment [1,2]. Such adverse effects may develop after chest irradiation in childhood cancers, lung, esophageal or breast cancer or Hodgkin's lymphoma [3,4]. These often unattributed complications cause deterioration in quality of life of long-surviving patients, extra health care costs,

\footnotetext{
* Corresponding author at: Cardiovascular Research Group, Department of Biochemistry, University of Szeged Dóm tér 9, Szeged, H-6720, Hungary.

E-mail address: aniko.gorbe@pharmahungary.com (A. Görbe).

1 Both authors contributed equally.
}

and lead occasionally to fatal outcomes. Although the application of modern radiotherapy planning and delivery significantly improves the radiation protection of the heart, in many cases, the entire heart or a part of it still receives a dose sufficient to cause long-term adverse effects. Notably, the evolving use of intensity-modulated radiotherapy (IMRT) will increase the volume of non-target tissues irradiated with low dose.

The development of radiation-induced heart diseases is dosedependent, and is more likely if radiation exposure occurs at a younger age $[5,6]$. Radiogenic ischemic heart disease, due to atherosclerotic changes of the coronary arteries, is indistinguishable from other etiologies that cause angina or myocardial infarct. Robust epidemiological data on such cardiovascular disease originates from breast cancer studies. Darby et al., analyzing the SEER database of more than 300,000 patients, found that among those 
who received adjuvant radiotherapy, the patients with left sided tumors had a significantly increased risk of cardiac death due to cardiovascular diseases or myocardial infarction, appearing 10 years after the irradiation, and increasing further thereafter [7,8]. It seems likely, that the radiogenic damage of the macrovasculature of the heart occurs after the exposure of these structures to relatively high doses. Animal experiments revealed inflammatory and oxidative damage leading to the formation of typical atherosclerotic plaques $[4,9]$. Radiation-induced diffuse myocardium changes include microvasculature abnormalities, degenerative cardiomyocyte and interstitial fibrotic changes. Such abnormalities may develop after even low dose radiation exposure, and can result in the deterioration of the heart's pump function or in cardiac conduction abnormalities [10]. Cilliers et al., investigated radiationinduced time-dependent changes of the myocardium in Wistar rats [11]. Interestingly, the radiation induced structural changes of the endothelial cells and myocytes developed early after the irradiation, and were accompanied by a transitory depression of the mechanical function of the heart; 100-180 days after the irradiation, only interstitial inflammation and fibrosis were present. Radiation induces inflammatory responses, and activates senescence pathways; there is a need to test new agents that could prevent these cellular responses.

Growth hormone-releasing hormone (GHRH) was first identified in humans as a hypothalamic peptide hormone which primarily regulates the production and release of pituitary growth hormone (GH) [12]. Recently, the expression of GHRH has also been demonstrated in a series of normal and cancerous tissues [13]. The pituitary receptor of GHRH ( $p$ GHRHR) belongs to the class type-II G protein-coupled receptors [14] the binding induces the production of cAMP that triggers a series of intracellular signaling cascades. The presence of its splice variants (mainly SV1, less importantly SV2, SV3) has been demonstrated in a series of peripheral normal tissues and a variety of cancers [15-17]. Stimulation of the GHRHR results in the activation of the ERK1/2, AKT, JAK2/STAT3, PI3K/AKT pathways [18]. Numerous experimental data support the autocrine-paracrine role of the GHRH system in regeneration of tissue. GHRH has been shown to promote survival and inhibit apoptosis in cardiomyocytes in vitro despite serum starvation or isoproterenol treatment [19]. The expression and activation of pGHRHR after GHRH administration were demonstrated in both adult rat ventricular myocytes and in H9c2 embryonic rat heart cells, which expressed pGHRHR [20].

GHRH prevented death of adult rat cardiac myocytes induced by serum starvation or by isoproterenol treatment which was antagonized by antagonistic analog of GHRH, JV-1-36. These protective effects were mediated by the activation of the extracellular signal -regulated kinase (ERK)1/2 and phosphoinositide-3 kinase (PI3K)/Akt signaling pathways. Additionally, isolated rat hearts subjected to ischemia-reperfusion (I/R) injury were protected by the administration of GHRH before ischemia, which was abolished if co-administered with JV-1-36 [19]. Penna at al. demonstrated similar results in the isolated rat heart model; the administration of GHRH at the onset of reperfusion reduced the size of the infarct, and this effect was abrogated if antagonistic analog of GHRH, JV-1-36 was co-administered [21].

Kanashiro-Takeuchi demonstrated that the administration of the GHRH agonist, JI-38, reversed ventricular remodeling and enhanced functional recovery after myocardial infarction, while reducing experimental infarct size in rats [22]. These effects were absent if a GHRH antagonist was co-administered, or by treatment with GH only. These effects point to the role of a GHRHR-mediated mechanism.

Following the demonstration of beneficial results of the J.I. class of agonistic analogs of GHRH in multiple fields, new classes of GHRH agonists have been developed with the ultimate goal of clinical use
Table 1

Cell survival in function of radiation dose. The 24-h cultures were exposed to different radiation doses $(5,10,15,20 \mathrm{~Gy})$, and cell loss was detected at different latency times $(0,24,48,72,96,120 \mathrm{~h})$. Data are expressed in percent of unirradiated control (mean $\pm \mathrm{SEM}$ ).

\begin{tabular}{lllll}
\hline \multicolumn{4}{l}{ Cell survival in ratio to control (\%) } \\
\hline Time after irradiation & 5 Gy & 10 Gy & 15 Gy & 20 Gy \\
\hline $0 \mathrm{~h}$ & $100 \pm 2$ & $98 \pm 2$ & $95 \pm 2$ & $96 \pm 3$ \\
$24 \mathrm{~h}$ & $76 \pm 2$ & $75 \pm 3$ & $79 \pm 4$ & $89 \pm 6$ \\
$48 \mathrm{~h}$ & $63 \pm 2$ & $50 \pm 2$ & $43 \pm 1$ & $44 \pm 1$ \\
$72 \mathrm{~h}$ & $58 \pm 3$ & $49 \pm 3$ & $43 \pm 3$ & $42 \pm 2$ \\
$96 \mathrm{~h}$ & $71 \pm 7$ & $78 \pm 8$ & $53 \pm 3$ & $49 \pm 3$ \\
$120 \mathrm{~h}$ & $50 \pm 2$ & $38 \pm 1$ & $37 \pm 1$ & $39 \pm 2$ \\
\hline
\end{tabular}

[23]. As noted some of them have been tested in the experimental myocardial infarct rat model, which confirmed the cardioprotective effects of GHRH agonists by measurement of infarct size and heart function $[23,24]$.

Since radiation triggers similar mechanisms as other cellular stresses, such as starvation and hypoxia, we hypothesized that GHRH and its receptor(s) might have a role in the recovery after irradiation. We therefore set out to study the effects of GHRH and its agonistic analogs in vitro, in newborn rat cardiomyocytes (NRVM), under different conditions.

\section{Materials and methods}

These experiments conform the National Institutes of Health Guide for the Care and Use of Laboratory Animals (NIH Pub. No. 8523 , Revised 1996) and was approved by the local ethics committee at the University of Szeged.

\subsection{Preparation of cultures of primary neonatal rat cardiac myocytes}

Neonatal rat cardiac myocytes (NRVM) were isolated as previously described [25]. Briefly, newborn Wistar rats were disinfected with $70 \%$ ethanol and then killed by cervical dislocation. Hearts were excised and transferred to cold phosphate-buffered saline (PBS), $\mathrm{pH}$ 7.2. The ventricles were separated, minced gently by fine forceps and digested in $0.25 \%$ trypsin solution ( $5 \mathrm{ml} /$ heart) at $37^{\circ} \mathrm{C}$ for $25 \mathrm{~min}$. The cell suspension was then centrifuged at $2000 \mathrm{RPM}$ at $4{ }^{\circ} \mathrm{C}$ for $15 \mathrm{~min}$. Pellets were resuspended in growth medium (Dulbecco's MEM supplemented with $10 \%$ fetal bovine serum [FBS], $0.1 \%$ glutamine, $0.1 \%$ Antibiotic/Antimycotic solution) and plated onto 6well plates to eliminate fibroblasts at $37^{\circ} \mathrm{C}$ for $90 \mathrm{~min}$ (pre-plating step). Cells of the supernatant were then re-plated onto fresh 6 - and 96-well plates and flasks $\left(5 \times 10^{5}, 15 \times 10^{4}\right.$ and $4 \times 10^{6}$ cells/well, respectively). NRVM were supplied with $2 \mathrm{ml}, 150 \mu \mathrm{l}$ and $20 \mathrm{ml}$ per well growth medium with or without $10 \%$ FBS in 6-well, 96-well plates and flasks, respectively, and were incubated at $37^{\circ} \mathrm{C}$ and $5 \%$ $\mathrm{CO}_{2}$. The experiments were started $24 \mathrm{~h}$ after plating.

\subsection{Irradiation of cell cultures}

The cell cultures were irradiated $24 \mathrm{~h}$ after plating, using a linear accelerator (Siemens Primus, Siemens Medical Solutions, USA). The plates were irradiated with $6 \mathrm{MV}$ energy photon beams with opposing field technique. To achieve a homogeneous dose distribution in the sample, $2 \mathrm{~cm}$ thick PMMA sheets were applied.

\subsection{Testing of GHRH agonist treatment}

First, the effects of synthetic human GHRH (hGHRH) (Bertin Pharma, Montigny le Bretonneux, France) was tested at concentrations of $1,10,50$, and $100 \mathrm{nM}$ in unirradiated and irradiated cell 
A

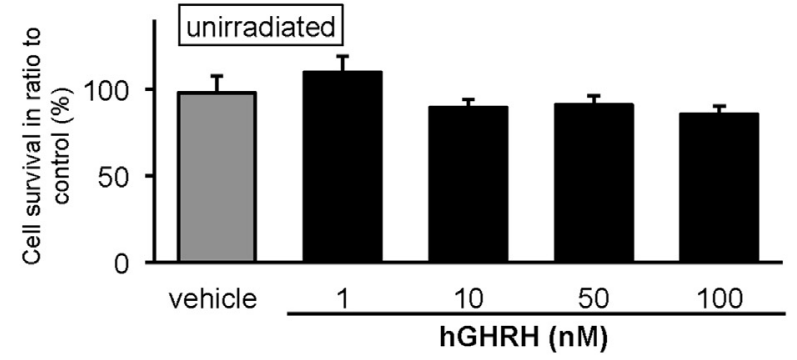

B

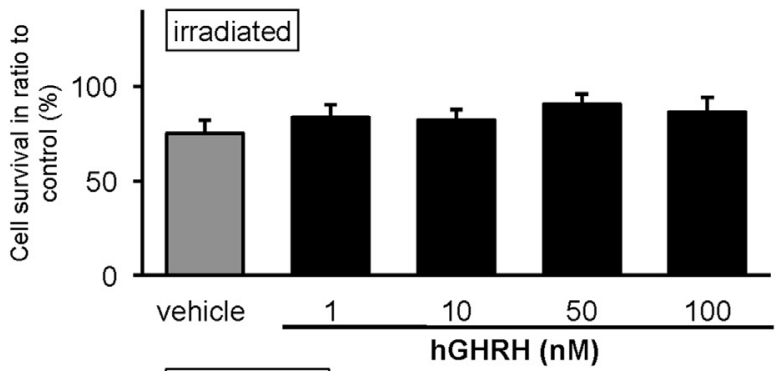

C

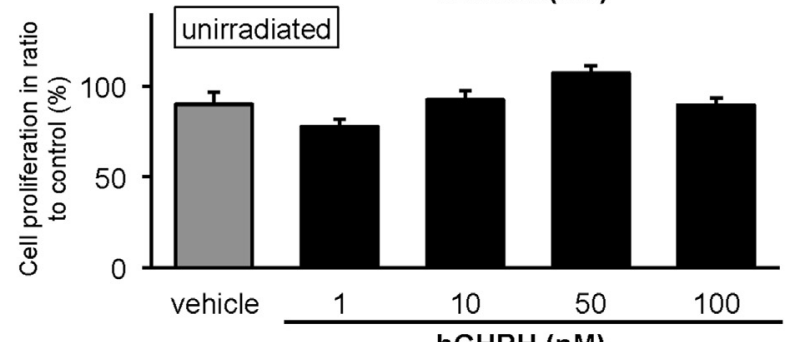

D

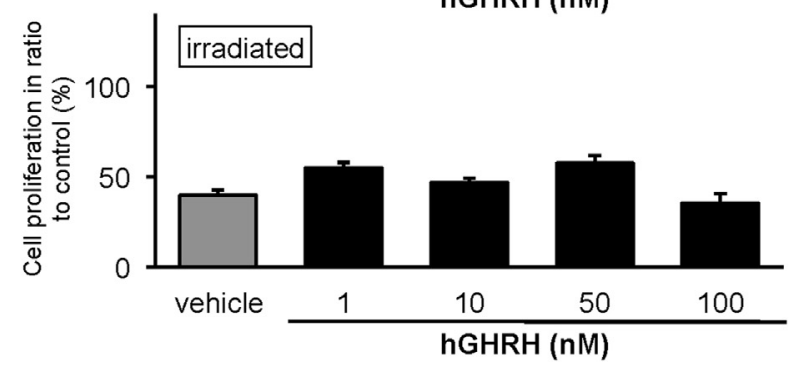

Fig. 1. Viability of unirradiated (A) and irradiated (B) NRVM after hGHRH treatment $(48 \mathrm{~h})$. The effects of hGHRH on the proliferation of unirradiated and irradiated NRVM are shown in panels $C$ and $D$, respectively. Data are expressed as mean \pm SEM in comparison to control (100\%); ${ }^{*} \mathrm{p}<0.05, \mathrm{n}=8-16$ in each group.

cultures. Next, GHRH agonists, JI-34 and MR-356, were studied both in unirradiated and irradiated cell cultures at concentrations of 1 , $10,50,100$ and $500 \mathrm{nM}$ in cultures with or without $1 \%$ FBS supplementation (for JI-34). Cell viability and proliferation assays were performed $48 \mathrm{~h}$ thereafter.

NRVM cultures maintained in FBS-supplemented medium were also studied for GHRHR expression and possible involved signaling pathways via Western blot analyses as follows: 1. non-irradiated, non-treated, 2. non-irradiated, JI-34-treated, 3. irradiated, nontreated, 4. irradiated and JI-34-treated; in these experiments, JI-34 was applied at the most effective concentration of $10 \mathrm{nM}$. Cells were collected 1 and $48 \mathrm{~h}$ after the irradiation.

\subsection{Cell viability and proliferation assays}

Both tests were performed following the respective experimental procedure (irradiation and/or treatment). For the assessment of cell viability, NRVM were incubated with $1 \mu \mathrm{M}$ calcein acetoxymethyl ester (calcein-AM, Sigma, St Louis, MO) at room temperature for $30 \mathrm{~min}$. Fluorescence intensity was measured with a fluorescence plate reader (Fluostar Optima, BMG Labtech, Orten-
A

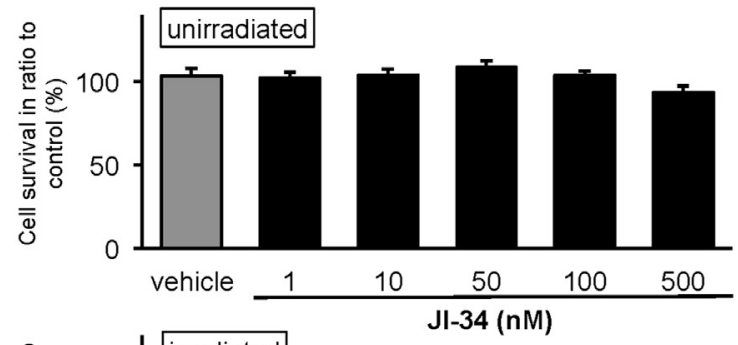

B

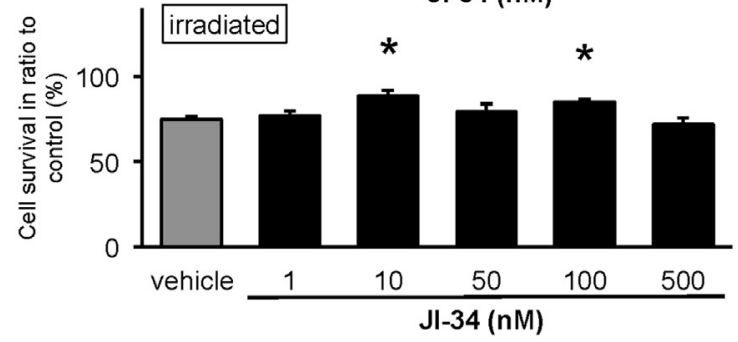

C

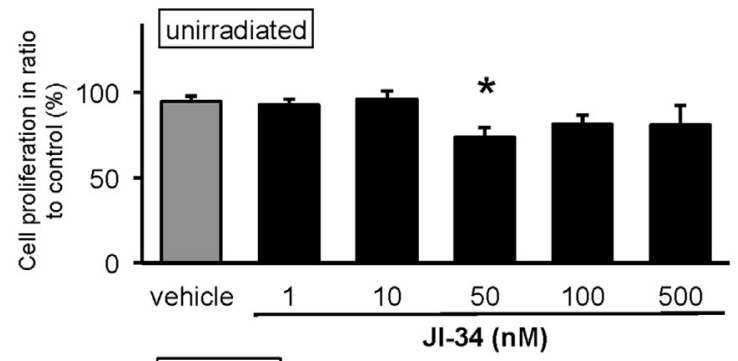

$\mathrm{D}$

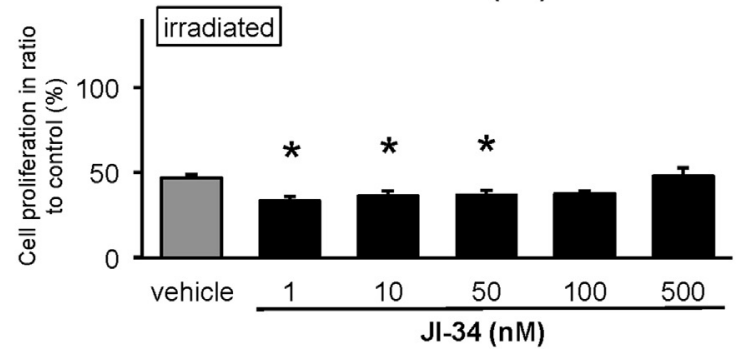

Fig. 2. Viability of unirradiated (A) and irradiated (B) NRVM after JI-34 treatment $(48 \mathrm{~h})$. Bromodeoxyuridine (BrdU) proliferation assay performed in unirradiated (C) and irradiated NRVM (D), $48 \mathrm{~h}$ after the treatment with JI-34. Data are expressed as mean $\pm S E M$; in comparison to unirradiated untreated control $(100 \%)$. ${ }^{*} \mathrm{p}<0.05$, $\mathrm{n}=8-16$ in each group.

berg, Germany) [26]. Cell viability was compared to that of vehicle control. Each plate contained non-irradiated columns serving as technical controls.

For the assessment of cell proliferation the NRVM cultures were incubated and labeled with $10 \mu \mathrm{l} /$ well 5-bromo-2'-deoxyuridine (BrdU) (Cell Proliferation ELISA, BrdU (colorimetric), Roche, Germany) labeling solution at $37^{\circ} \mathrm{C}, 5 \% \mathrm{CO}_{2}$ for $20 \mathrm{~h}$. Then the labeling medium was removed, the cells fixed, and the DNA was denatured in one step with fix/denature solution. Then an antiBrdU mouse monoclonal antibody was added followed by an HRP conjugated secondary antibody to detect the incorporated BrdU. The absorbance intensity was measured with a plate reader.

\subsection{Western blot}

After the indicated time of incubation, cell cultures were washed with D-PBS and incubated for $5 \mathrm{~min}$ in homogenization buffer $(1 \mathrm{x}$ RIPA supplemented with a protease and phosphatase inhibitor cocktail). Then cells were scraped, collected and sonicated with an ultrasound homogenizer for $10 \mathrm{~s}$ on ice. The homogenate was centrifuged at $11800 \mathrm{RPM}, 4{ }^{\circ} \mathrm{C}$ for $10 \mathrm{~min}$ (Hettich Universal $320 \mathrm{R}$ Centrifuge, Andreas Hettich GmbH and Co., Tuttlingen, 
A

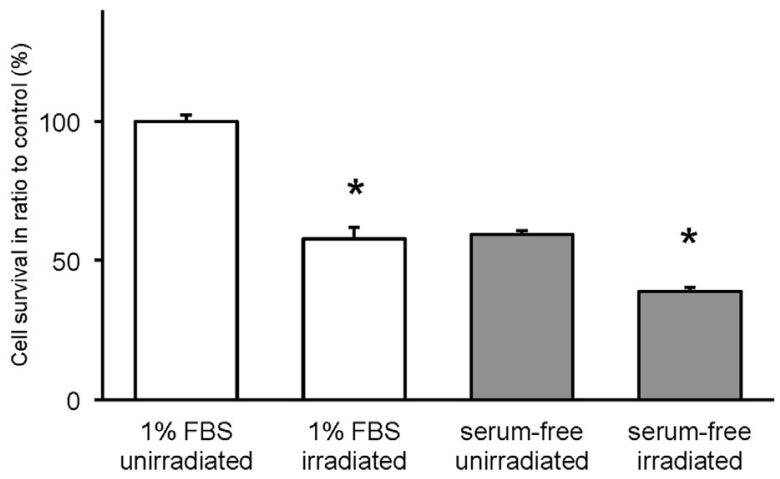

B

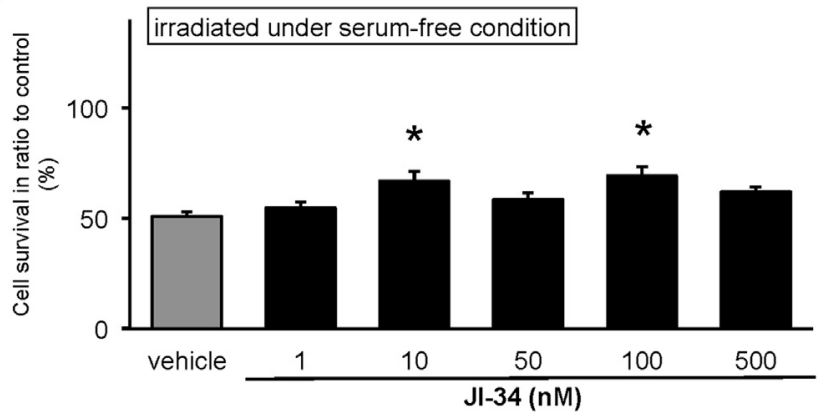

Fig. 3. NRVM cell viability cultured with or without $1 \%$ FBS. Unirradiated and irradiated cultures were compared after $48 \mathrm{~h}$ of latency time (A). Viability of irradiated nrcm NRVM cells after JI-34 treatment, cultured without FBS supplementation; data are expressed as mean \pm SEM; in comparison to control $(100 \%)$. ${ }^{*} \mathrm{p}<0.05, \mathrm{n}=8-16$ in each group (B).

Germany); the supernatant was transferred into a concentrating tube (Amicon ${ }^{\circledR}$ Ultra-4 Centrifugal Filter Units, $10 \mathrm{kDa}$ MWCO), and was centrifuged again at $6300 \mathrm{RPM}, 4{ }^{\circ} \mathrm{C}$ for $20 \mathrm{~min}$. The concentrated sample was collected and stored at $-80^{\circ} \mathrm{C}$. Protein concentration was measured with bicinchoninic acid (BCA) assay (Pierce $^{\mathrm{TM}}$ BCA Protein Assay Kit, Thermo Fisher Scientific Inc., Waltham, MA USA) by reading the optical density at UV max of $560 \mathrm{~nm}$, and calculating automatically by the Anthos software.

For analysis of GHRHR expression 20- $\mu$ g samples of protein were loaded on $10 \%$ SDS-PAGE followed by the transfer of proteins onto a nitrocellulose membrane $(90 \mathrm{~V}, 1 \mathrm{~h})$. Membranes were then blocked overnight at $4{ }^{\circ} \mathrm{C}$ in $1 \%$ bovine serum albumin (BSA). Membranes were incubated both with GHRHR antibody (1:1000, ab76263, Abcam Inc., Cambridge, MA) and GAPDH antibody (1:5000, Cell Signaling Technology, Danvers, MA) for $1.5 \mathrm{~h}$ at room temperature in 1\% BSA (Cell Signaling Technology, Danvers, MA) and then anti-rabbit HRP secondary antibody (1:2000; 1:10000, Dako, Glostrup, Denmark) for $40 \mathrm{~min}$. Membranes were then developed with an enhanced chemiluminescence kit (GE HealthCare, Little Chalfont, UK), exposed to X-ray film (Kodak, Rochester, NY, US), and scanned [27].

For the analysis of ERK and Akt, equal amounts of protein $(20 \mu \mathrm{g})$ were mixed with reducing $5 \times$ Laemmli buffer, loaded and separated in $4-20 \%$ precast Tris-glycine SDS polyacrilamide gels (Bio-Rad Hungary Ltd., Budapest, Hungary). Proteins were transferred onto a polyvinylidene difluoride membrane (Bio-Rad Hungary Ltd., Budapest, Hungary) at $350 \mathrm{~mA}$ for $2 \mathrm{~h}$. Transfer was visualized with Ponceau staining (Sigma, St Louis, MO). Membranes were blocked with 5\% BSA (Santa Cruz Biotechnology, Inc., Heidelberg, Germany) in Tris-buffered saline containing $0.05 \%$ Tween-20 (0.05\% TBS-T; Sigma, St Louis, MO) at room temperature for $2 \mathrm{~h}$. Membranes were probed with primary antibodies (dilution $1: 1000$ ) overnight at $4{ }^{\circ} \mathrm{C}$ (phospho-Akt [Ser473] - \#9271; Akt \#9272; phospho-Erk1/2 [Thr202/Tyr204] - \#9106; Erk1/2 -\#9107;
A

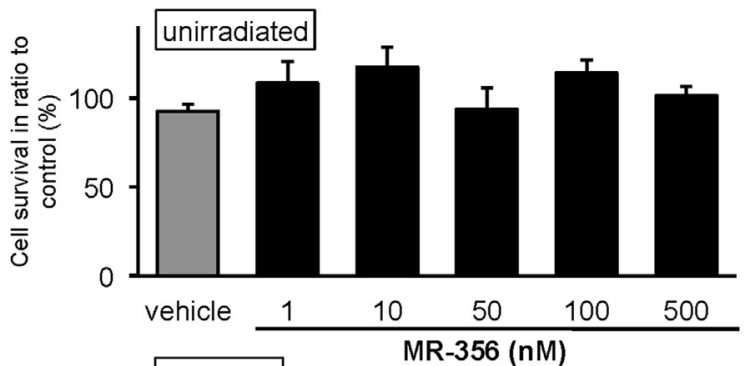

B

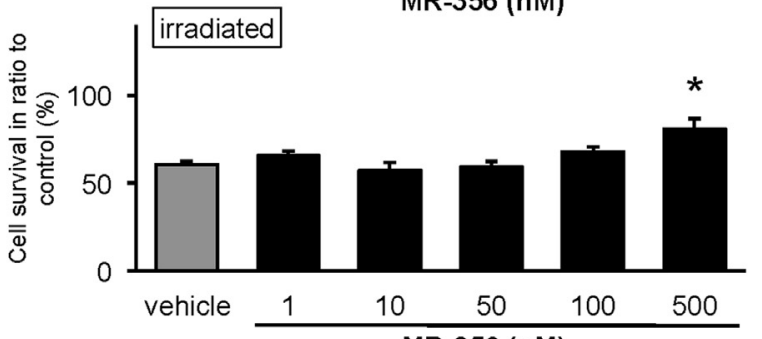

C

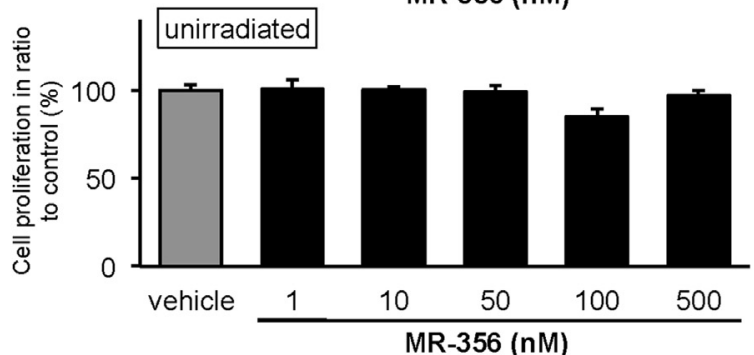

D

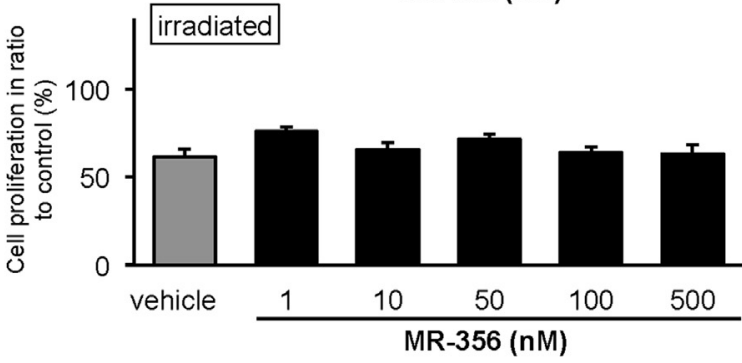

Fig. 4. Viability of unirradiated (A) and irradiated (B) NRVM after MR-356 treatment Bromodeoxyuridine (BrdU) proliferation assay performed in unirradiated (C) and irradiated NRVM (D) $48 \mathrm{~h}$ after the treatment with MR-356. Data are expressed as mean \pm SEM; in comparison to control $(100 \%){ }^{*} \mathrm{p}<0.05, \mathrm{n}=8-16$ in each group.

GAPDH - \#5174), and with corresponding HRP-conjugated secondary antibodies (Cell Signaling Technology, Danvers, MA) for $2 \mathrm{~h}$ at room temperature. Signals were detected with the chemiluminescence kit. Quantification was made by intensity ratio by Image Lab 4.1 (Image Lab ${ }^{\mathrm{TM}}$ Software, Bio-Rad Laboratories, Inc., California, USA). Antibodies detecting phosphorylated epitopes were removed with Pierce stripping buffer (Thermo Scientific Labor Kft., Budapest, Hungary) before incubation with antibodies detecting the total protein.

\subsection{Oxidative stress detection}

The presence of superoxide was detected with a plate reader using the oxidative fluorescent dye dihydroethidium (DHE) (Sigma St. Louis, MO; D7008). Cell membranes are freely permeable to DHE that fluoresces red when oxidized to ethidium in the presence of superoxide. The presence of general ROS production was detected by DCFH-DA (Sigma; D6883). Cardiac myocytes were rinsed with PBS, then incubated with $10 \mathrm{uM}$ DHE or DCFH-DA at room temperature for $60 \mathrm{~min}$ in a dark chamber, After removing 


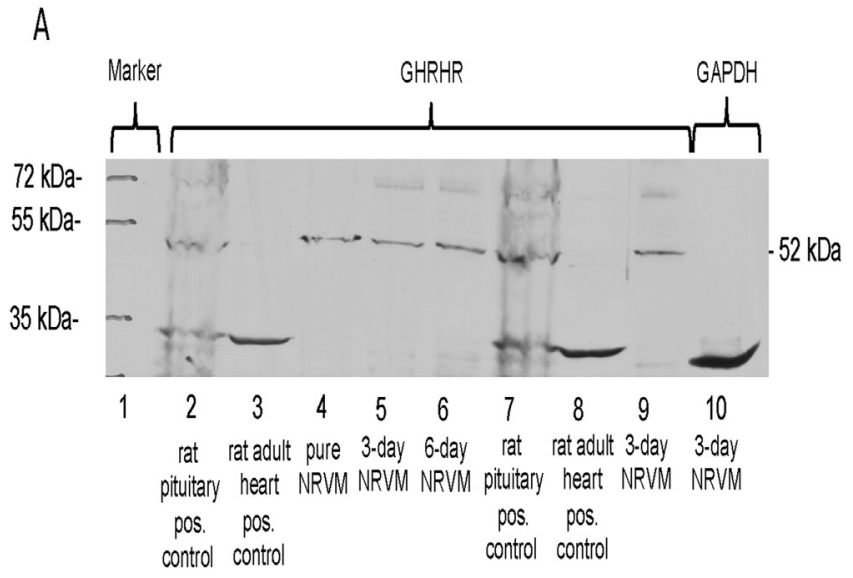

B
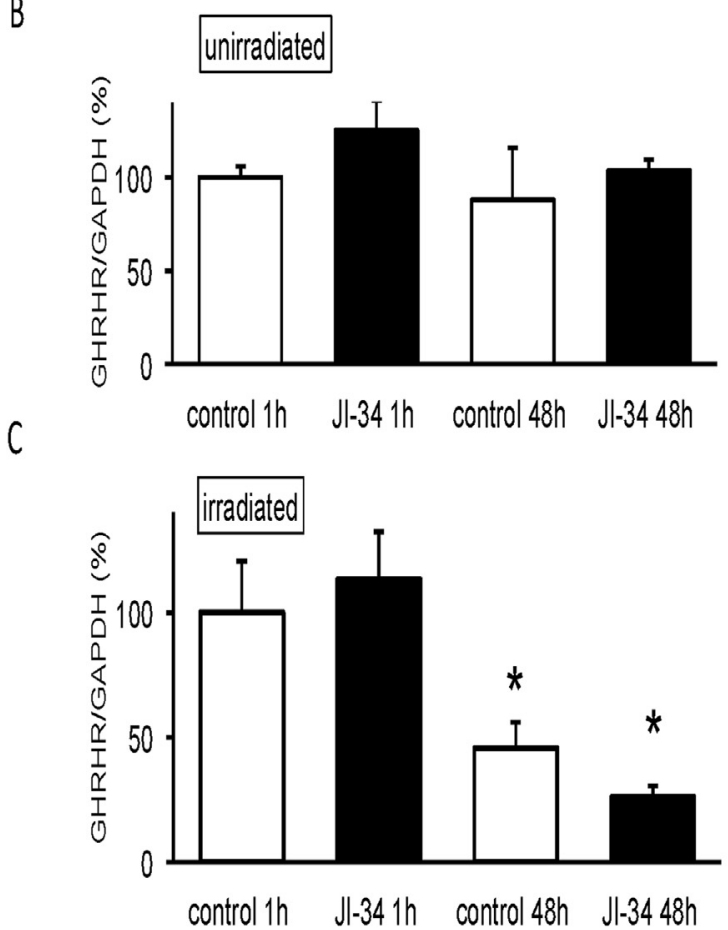

Fig. 5. Western blot analysis: pGHRHR and GAPDH housekeeping gene expression (A). The expression of GHRHR normalized to the GAPDH housekeeping gene in unirradiated (B) and irradiated (C) NRVM cultures. Western blots were performed both on untreated cells and cells treated with $10 \mathrm{nM} \mathrm{JI}-34$. Results are mean \pm SEM (expressed in\% as compared to non-treated cells); $\mathrm{n}=6$ sample/group, ${ }^{*} \mathrm{p}<0.05$.

extra dye with D-PBS ( $\mathrm{pH} 7.4$ ), the fluorescence intensity was measured [28].

\subsection{Statistical analysis}

Results are presented as a mean \pm SE. One-way analysis of variance (ANOVA) followed by Fisher's least significant difference (LSD) post-hoc tests or Dunnet's post-hoc tests were used to evaluate differences between groups. Two experimental groups were analyzed with the $t$-test. Western blot results were analyzed with two-way analysis of variance (ANOVA). Differences were considered significant if $\mathrm{p}<0.05$.

\section{Results}

To determine optimal experimental conditions, NRVM were exposed to various radiation doses, and viability was measured fol-
A
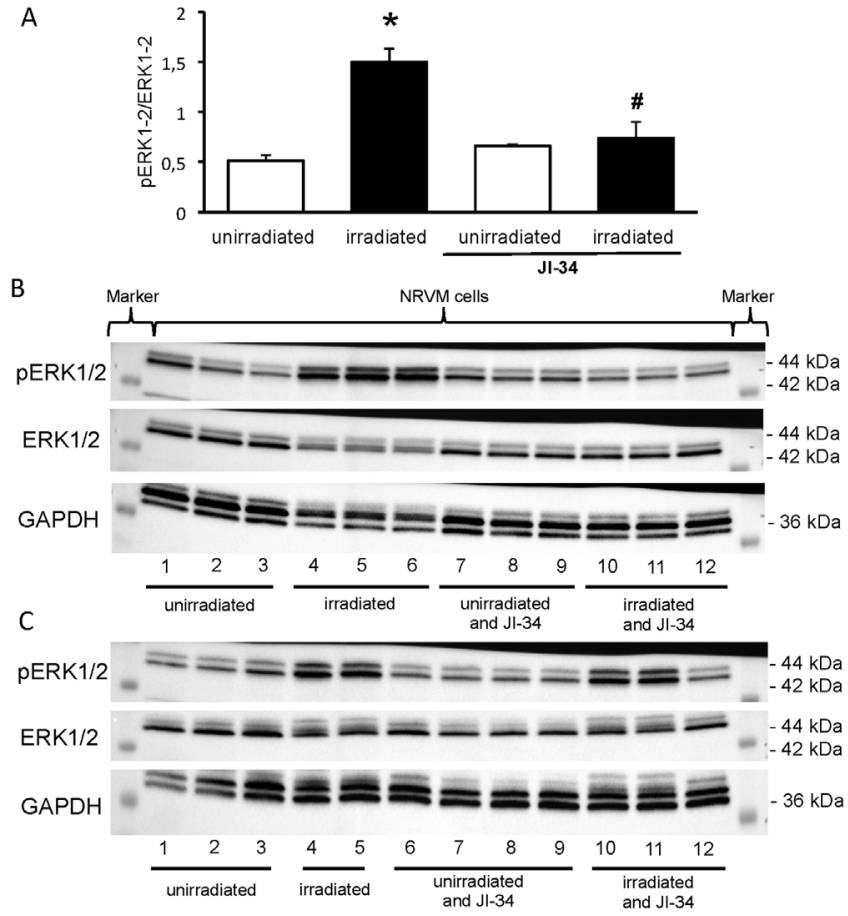

Fig. 6. The expression of pERK/ERK and the expression of GAPDH housekeeping gene in unirradiated and irradiated NRVM cultures. Western blots were performed both on untreated cells and cells treated with $10 \mathrm{nM} \mathrm{JI}-34$. Results are mean $\pm \mathrm{SEM}$; $\mathrm{n}=6$ sample/group * $\mathrm{p}<0.05$.

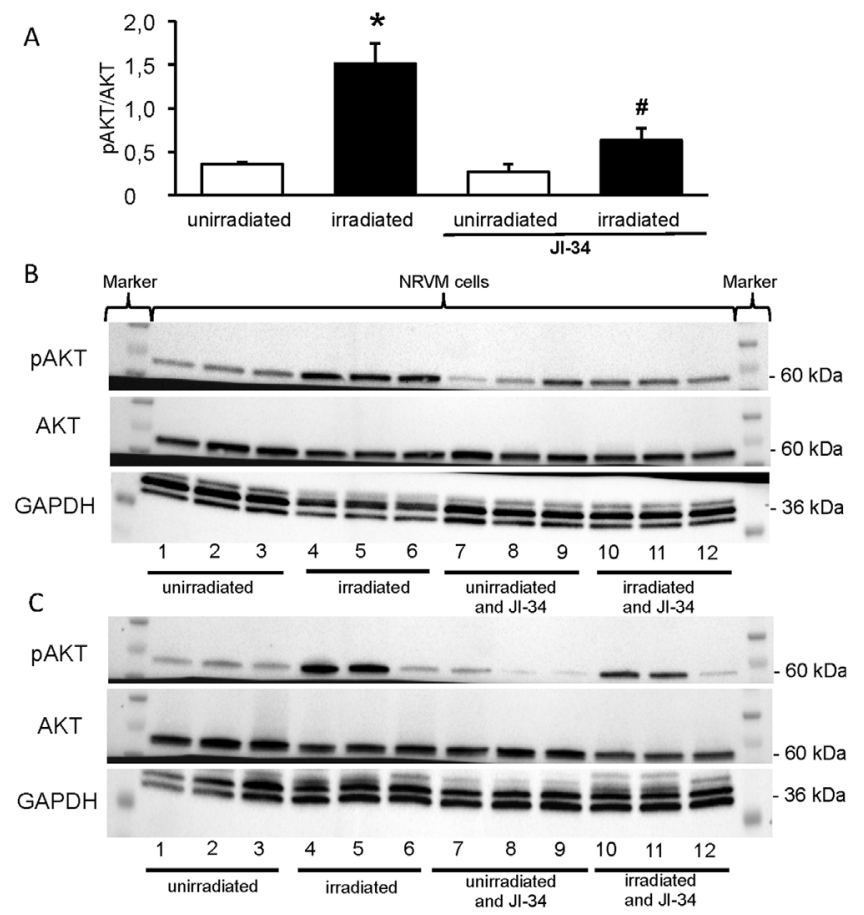

Fig. 7. The expression of pAkt/Akt and the expression of GAPDH housekeeping gene in unirradiated and $10 \mathrm{~Gy}$ irradiated NRVM cultures. Western blots were performed both on untreated cells and cells treated with $10 \mathrm{nM} \mathrm{JI}-34$. Results are mean \pm SEM; $\mathrm{n}=6$ sample/group ${ }^{*} \mathrm{p}<0.05$.

lowing varying latency times (Table 1). A significant cell loss of $50 \%$ was obtained after $10 \mathrm{~Gy}$ dose of radiation and latency time of $48 \mathrm{~h}$. This set of conditions was chosen and applied throughout all the experiments. 
A

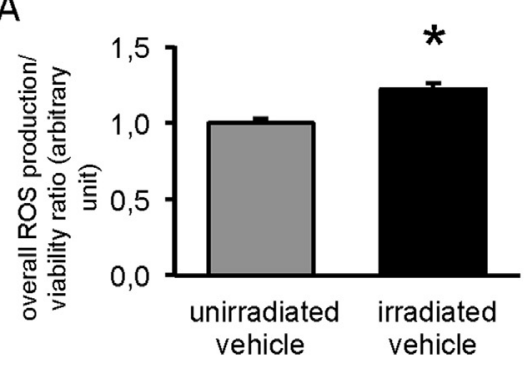

B

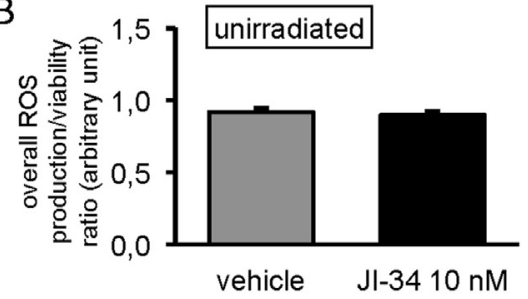

C

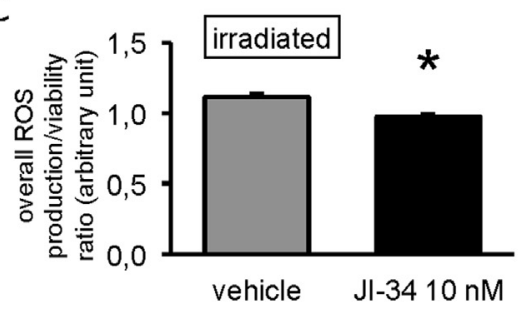

D

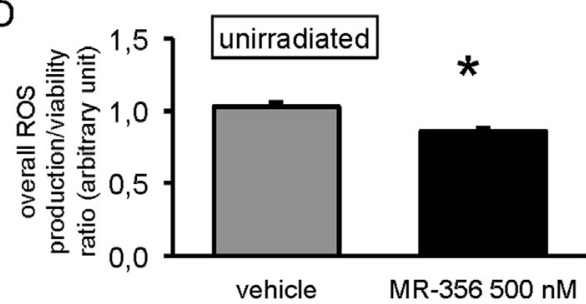

$\mathrm{E}$

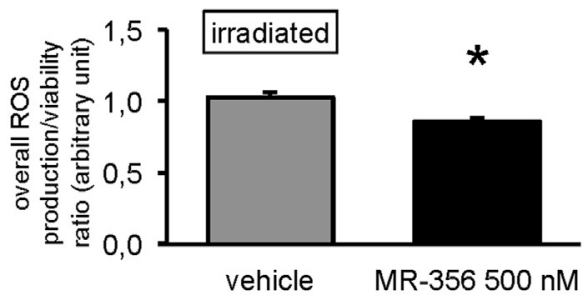

$\mathrm{F}$

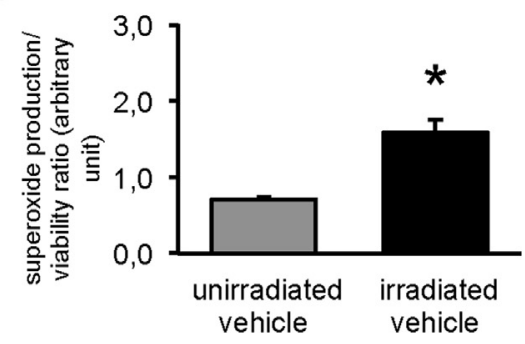

G

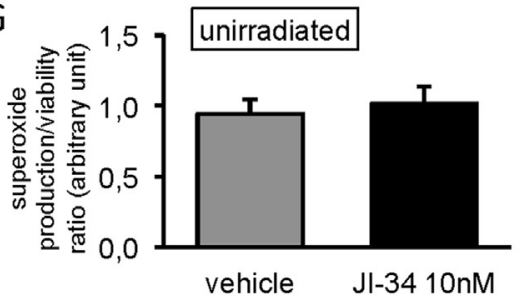

$\mathrm{H}$

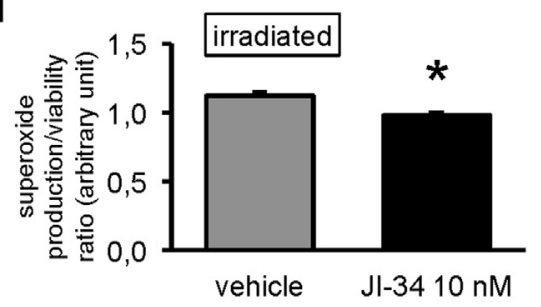

J
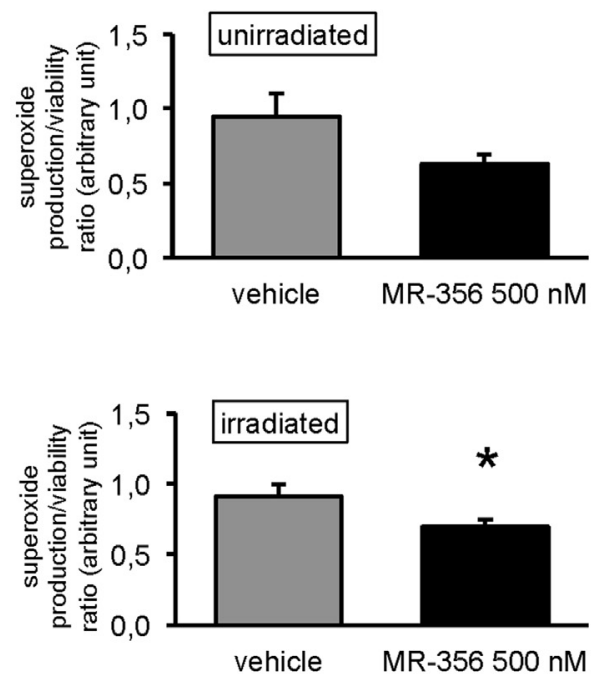

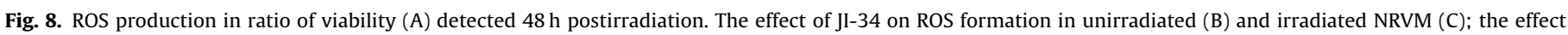

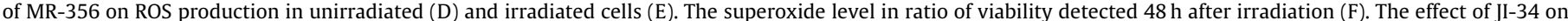

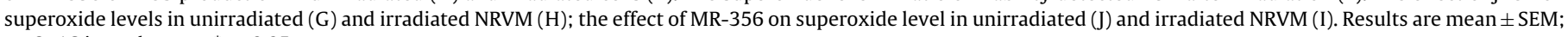
$\mathrm{n}=8-16$ in each group ${ }^{*} \mathrm{p}<0.05$.

First, the effect of hGHRH was tested on cell viability and cell proliferation in unirradiated and irradiated NRVM cultures. hGHRH did not significantly influence cell survival as compared to control (Fig. 1A and B). hGHRH was tested for its effect on cell proliferation via the BrdU incorporation assay. Cell proliferation of both irradiated and non-irradiated cells was slightly stimulated by hGHRH at a concentration of $50 \mathrm{nM}$ (Fig. 1C).

The effects of the GHRH agonists, JI-34 and MR-356, were first tested in unirradiated NRVM. The administration of JI-34 had no effect on cell viability at concentrations of $1-500 \mathrm{nM}$ (Fig. 2A). However, in irradiated cells, JI-34 showed a protective effect at concentrations of 10 and $100 \mathrm{nM}$ (Fig. 2B). Anti-proliferative effect of JI-34 was detected at $50 \mathrm{nM}$ in unirradiated and at $1-50 \mathrm{nM}$ in irradiated cultures (Fig. 2C and D). We have tested the same parameters under serum-deprived conditions to test the possible effects of the absence of $1 \%$ FBS including the avoidance of the binding of the analogs to the plasma proteins. NRVM cultures maintained in serum-free medium for 2 days contained roughly $50 \%$ less cells both in the irradiated and unirradiated plates (Fig. 3A). Again, a strong protective effect of JI-34 was detected after irradiation, at concentrations of 10 and $100 \mathrm{nM}$ (Fig. 3B). The GHRH agonist, MR-356, had no significant effect on cell survival in unirradiated NRVM cultures 
(Fig. 4A), but prevented cell loss at a concentration of $500 \mathrm{nM}$ after irradiation (Fig. 4B). No proliferative effect of MR-356 was detected in either the unirradiated or the irradiated cultures (Fig. 3C and D).

In order to investigate the expression of GHRHRs in NRVM at the protein level, Western blot analysis was performed using an antibody able to detect pGHRHRs. A $52 \mathrm{kDa}$ protein isoform was readily detected in the samples together with GAPDH used as internal control (Fig. 5A). This $52 \mathrm{kDa}$ glycosylated GHRHR was expressed in both irradiated and unirradiated cells. The treatment of cells with JI-34, did not influence the expression of GHRHRs (probably due to low dose of agonist) in irradiated (Fig. 5B) or unirradiated NRVM (Fig. 5C). Irradiation caused significant decline in receptor expression after $48 \mathrm{~h}$

For further investigation of intracellular action of GHRH agonists, the activation of RISK/SAFE pro-survival kinases was tested. The phosphorylation ratio of ERK significantly increased after the irradiation with $10 \mathrm{~Gy}$, which was significantly attenuated by JI34 treatment (Fig. 6). Likewise, the phosphorylation ratio of AKT significantly increased after the $10-\mathrm{Gy}$ irradiation which was significantly attenuated after JI-34 treatment (Fig. 7).

Next, JI-34 agonist was additionally tested for its possible effect on ROS production. Both the overall level of ROS and that of superoxide significantly increased $48 \mathrm{~h}$ after the irradiation. JI-34 treatment significantly decreased overall ROS production after irradiation, while MR-356 decreased its level in both irradiated and unirradiated cultures. Both agonists decreased superoxide level significantly in irradiated cultures (Fig. 8).

\section{Discussion}

In this in vitro NRVM model, the agonistic analogs of GHRH, JI34 and MR-356, reduced radiation-induced cell loss. This is the first demonstration that GHRH agonists exert protective effect in irradiated cardiac myocytes via the attenuation of ROS formation and other mechanisms present in different kinds of stress situations. These data and the expression of GHRHR in NRVM contribute to the previous findings on the role of the GHRH system in cardiomyocyte regeneration. Radiogenic late cardiac cytotoxicity is widely-studied in in vivo models, however, limited experience is available with the use of in vitro models appropriate for the study of acute radiogenic effects. The present study seems to provide reproducible conditions for further studies.

The mechanism of cardiocytoprotection of GHRH agonists is not fully clarified, and probably depends on the system examined. The antiapoptotic effects of GHRH agonists have been demonstrated in in vivo experimental infarcts in the rat. The chronic administration of the GHRH-agonist JI-38 upregulated the expression of the anti-apoptotic BCL2, while down-regulated that of the proapoptotic BAX gene, and increased the proliferation of cardiac precursor cells in experimental heart infarcts $[22,24]$. In a similar system, GHRH agonists reduced the expression of inflammatory and profibrotic markers [20]. In H9c2 cardiomyoblasts cultured under serum-deprived condition, agonistic analogs of GHRH repressed the expression of a series of genes related to cardiac remodelling [20]. Some studies conclude to that GHRH or its agonistic analogs modulate the kinases included in the RISK and SAFE pathways $[19,21]$. GHRH treatment prevented apoptosis induced by serum starvation or isoproterenol treatment in cardiac myocytes through the interaction with multiple signalling mechanisms involving the cAMP/protein kinase A, ERK $1 \frac{1}{2}$ and PI3K/Akt pathways [19]. GHRH protected the rat heart from I/R-caused injury administered at reperfusion via activation of the RISK and SAFE pathways, as measured 20 min after the start of reperfusion [21]. The early activation of ERK $1 / 2$ and Akt was detected by Granata, in serum-deprived isolated cardiac myocytes [19]. In our study, the post-irradiation administration of GHRH agonists also strongly affected the activation of the SAFE/RISK signaling pathways. Both JI-34 and MR-356 treatment significantly decreased phosphorylation of Akt and ERK after $48 \mathrm{~h}$ of latency time. Their protective effect may be explained by this phenomenon since irradiation induces the MAPK pathway and the phosphorylation of ERK via ROS formation [29]. In fact, our study indicates that the agonistic analogs of GHRH directly influence oxidative stress. ROS formation readily detectable $48 \mathrm{~h}$ after the irradiation was effectively reduced by the post-irradiation administration of JI-34 and MR-356. The pretreatment of C3H mice with the GHRH antagonist, JMR-132, caused a response dependent on the radiation dose of whole body radiation [30,31].

The effects of GHRH or the agonistic analogs are mediated by the GHRHR. The administration of GHRH antagonists together with GHRH or its agonistic analogs abolished its protective effects on cardiomyocytes [19,21]. We believe that GHRH and its receptors have physiological roles in the recovery from cell injury, and that the explanation for our findings in NRVM is the presence and function of the GHRHR. Granata et al. have demonstrated both the mRNA and protein expression of the pGHRHR in cardiac cells [19]. The pGHRHR has been detected in rat hearts by means of Western blotting, immunohistochemistry and ligand binding assay [24]. In consistence with these findings, we showed the presence of a $52 \mathrm{kDa}$ protein isoform of GHRHR, with Western blotting; the expression of this protein declined by time in irradiated NRVM, irrespective of whether JI-34 treatment was applied. The difference irradiation made, may point to the role of the GHRH system in cell recovery after radiation injury.

In conclusion, the present study provides a well-reproducible in vitro cell culture model for the investigation of irradiationinduced cardiomyocyte damage, in which GHRH analogs have been tested. GHRH agonistic analogs, JI-34 and MR-356 exerted protective effects on radiation-induced cell damage, hence GHRH agonists should be tested in vivo as potential protective agents against radiogenic heart damage.

\section{Declaration of interest}

The authors report no conflict of interest. The authors alone are responsible for the content and writing of the paper.

\section{Acknowledgements}

The authors would like to thank Dr. Miklós Jászberényi (Department of Pathophysiology, University of Szeged) for his support and guidance throughout the study. This study was supported by National Development Agency - New Hungary Development Plan TAMOP-4.2.2.A-11/1/KONV-2012-0035 and TAMOP-4.2.2/B-10/12010-0012 and National Research, Development and Innovation Office - NKFIH PD106001 (NKFI). Dr. Görbe held Bolyai János fellowship from the Hungarian Academy of Sciences.

Professor Ferdinandy was a Szentágothai Fellow of the National Program of Excellence (TAMOP 4.2.4.A/2-11-1-2012-0001).

\section{Appendix A. Supplementary data}

Supplementary data associated with this article can be found, in the online version, at http://dx.doi.org/10.1016/j.phrs.2016.07. 036.

\section{References}

[1] M.J. Adams, P.H. Hardenbergh, L.S. Constine, S.E. Lipshultz, Radiation-associated cardiovascular disease, Crit. Rev. Oncol. Hematol. 45 (2003) 55-75. 
[2] N. Andratschke, J. Maurer, M. Molls, K.R. Trott, Late radiation-induced heart disease after radiotherapy. Clinical importance, radiobiological mechanisms and strategies of prevention, Radiother. Oncol. 100 (2011) 160-166.

[3] B.M.P. Aleman, D. Re, V. Diehl, The role of radiation therapy in patients with Hodgkin's lymphoma, Curr. Hematol. Malig. Rep. 2 (2007) 151-160.

[4] F.A. Stewart, I. Seemann, S. Hoving, N.S. Russell, Understanding radiation-induced cardiovascular damage and strategies for intervention, Clin. Oncol. (R. Coll. Radiol.) 25 (2013) 617-624.

[5] S. Schultz-Hector, K.R. Trott, Radiation-induced cardiovascular diseases: is the epidemiologic evidence compatible with the radiobiologic data? Int. J. Radiat. Oncol. Biol. Phys. 67 (2007) 10-18.

[6] F.A. Stewart, S. Heeneman, J. Te Poele, J. Kruse, N.S. Russell, M. Gijbels, M. Daemen, Ionizing radiation accelerates the development of atherosclerotic lesions in ApoE- - -mice and predisposes to an inflammatory plaque phenotype prone to hemorrhage, Am. J. Pathol. 168 (2006) 649-658.

[7] S. Darby, P. McGale, C.W. Taylor, R. Peto, Long-term mortality from heart disease and lung cancer after radiotherapy for early breast cancer: prospective cohort study of about 300,000 women in US SEER cancer registries, Lancet Oncol. 6 (2005) 557-565.

[8] S.C. Darby, M. Ewertz, P. McGale, A.M. Bennet, U. Blom-Goldman, D. Brønnum, C. Correa, D. Cutter, G. Gagliardi, B. Gigante, M.B. Jensen, A. Nisbet, R. Peto, K. Rahimi, C. Taylor, P. Hall, Risk of ischemic heart disease in women after radiotherapy for breast cancer, N. Engl. J. Med. 368 (2013) 987-998.

[9] K. Gabriels, S. Hoving, I. Seemann, N.L. Visser, M.J. Gijbels, J.F. Pol, M.J. Daemen, F.A. Stewart, S. Heeneman, Local heart irradiation of ApoE(-/-) mice induces microvascular and endocardial damage and accelerates coronary atherosclerosis, Radiother. Oncol. 105 (2012) 358-364.

[10] S. Schultz-Hector, Radiation-induced heart disease: review of experimental data on dose response and pathogenesis, Int. J. Radiat. Biol. 61 (1992) $149-160$.

[11] G.D. Cilliers, I.S. Harper, A. Lochner, Radiation induced changes in the ultrastructure and mechanical function of the rat heart, Radiother. Oncol. 16 (1989) 311-326.

[12] N. Ling, F. Esch, P. Böhlen, P. Brazeau, W.B. Wehrenberg, R. Guillemin, Isolation, primary structure, and synthesis of human hypothalamic somatocrinin: growth hormone-releasing factor, Proc. Natl. Acad. Sci. U. S. A 81 (1984) 4302-4306.

[13] H. Kiaris, I. Chatzistamou, A.G. Papavassilliou, A.V. Schally, Growth hormone-releasing hormone: not only a neurohormone, Trends Endocrinol. Metab. 22 (2011) 311-317

[14] B. Martin, R. Lopez de Maturana, R. Brenneman, T. Walent, M.P. Mattson, S. Maudsley, Class II G protein-coupled receptors and their ligands in neuronal function and protection, Neuromol. Med. 7 (2005) 3-36.

[15] S. Bellyei, A.V. Schally, M. Zarandi, J.L. Varga, I. Vidaurre, E. Pozsgai, GHRH antagonists reduce the invasive and metastatic potential of human cancer cell lines in vitro, Cancer Lett. 293 (2010) 31-40.

[16] G. Halmos, A.V. Schally, T. Czompoly, M. Krupa, J. Varga, Z. Rekasi, Expression of growth hormon relasing hormone and splice variants in human prostate cancer, J. Clin. Endocrinol. Metab. 87 (2002) 4707-4714.

[17] B. Kövári, O. Rusz, A.V. Schally, Z. Kahán, G. Cserni, Differential immunostaining of various types of breast carcinomas for growth hormone releasing hormone receptor-Apocrine epithelium and carcinomas emerging as uniformly positive APMIS, 122, 2014. 824-831.

[18] N. Barabutis, A. Siejka, A.V. Schally, N.L. Block, R. Cai, J.L. Varga, Activation of mitogen-activated protein kinases by a splice variant of GHRH receptor, J. Mol. Endocrinol. 44 (2010) 127-134.
[19] R. Granata, L. Trovato, M.P. Gallo, S. Destefanis, F. Settanni, F. Scarlatti, A. Brero, R. Ramella, M. Volante, J. Isgaard, R. Levi, M. Papotti, G. Alloatti, E. Ghigo, Growth hormone-releasing hormone promotes survival of cardiac myocytes in vitro and protects against ischaemia-reperfusion injury in rat heart, Cardiovasc. Res. 83 (2009) 303-312.

[20] R.M. Kanashiro-Takeuchi, L. Szalontay, A.V. Schally, L.M. Takeuchi, P. Popovics, M. Jaszberenyi, I. Vidaurre, M. Zarandi, R.Z. Cai, N.L. Block, J.M. Hare, F.G. Rick, New therapeutic approach to heart failure due to myocardial infarction based on targeting growth hormone-releasing hormone receptor, Oncotarget 6 (2015) 9728-9739.

[21] C. Penna, F. Settanni, F. Tullio, L. Trovato, P. Pagliaro, G. Alloatti, E. Ghigo, R. Granata, GH-releasing hormone induces cardioprotection in isolated male rat heart via activation of RISK and SAFE pathways, Endocrinology 154 (2013) 1624-1635.

[22] R.M. Kanashiro-Takeuchi, L.M. Takeuchi, F.G. Rick, R. Dulce, A.V. Treuer, V. Florea, C.O. Rodrigues, E.C. Paulino, K.E. Hatzistergos, S.M. Selem, D.R. Gonzalez, N.L. Block, A.V. Schally, J.M. Hare, Activation of growth hormone releasing hormone $(\mathrm{GHRH})$ receptor stimulates cardiac reverse remodeling after myocardial infarction (MI), Proc. Natl. Acad. Sci. U. S. A. 109 (2011) 559-563.

[23] R. Cai, A.V. Schally, T. Cui, L. Szalontay, G. Halmos, W. Sha, M. Kovacs, M. Jaszberenyi, J. He, F.G. Rick, P. Popovics, R. Kanashiro-Takeuchi, J.M. Hare, N.L. Block, M. Zarandi, Synthesis of new potent agonistic analogs of growth hormone-releasing hormone (GHRH) and evaluation of their endocrine and cardiac activities, Peptides 52 (2014) 104-112.

[24] R.M. Kanashiro-Takeuchi, K. Tziomalos, L.M. Takeuchi, A.V. Treuer, G. Lamirault, R. Dulce, M. Hurtado, Y. Song, N.L. Block, F. Rick, A. Kulkovits, Q. Hu J.L. Varga, A.V. Schally, J.M. Hare, Cardioprotective effects of growth hormone-releasing hormone agonist after myocardial infarction, Proc. Natl. Acad. Sci. U. S. A. 107 (2010) 2604-2609.

[25] A. Gorbe, Z. Giricz, A. Szunyog, T. Csont, D.S. Burley, G.F. Baxter, P. Ferdinandy, Role of cGMP-PKG signaling in the protection of neonatal rat cardiac myocytes subjected to simulated ischemia/reoxygenation, Basic Res. Cardiol. 105 (2010) 643-650.

[26] G. Szücs, Z. Murlasits, S. Török, G.F. Kocsis, J. Pálóczi, A. Görbe, T. Csont, C. Csonka, P. Ferdinandy, Cardioprotection by farnesol: role of the mevalonate pathway, Cardiovasc. Drugs Ther. 27 (2013) 269-277.

[27] C. Csonka, K. Kupai, P. Bencsik, A. Görbe, J. Pálóczi, A. Zvara, L.G. Puskas, T. Csont, P. Ferdinandy, Cholesterol-enriched diet inhibits cardioprotection by ATP-sensitive potassium channel activators cromakalim and diazoxide, Am. J. Physiol. Heart Circ. Physiol. 306 (2014) 405-413.

[28] T. Csont, E. Bereczki, P. Bencsik, G. Fodor, A. Görbe, A. Zvara, C. Csonka, L.G. Puskás, M. Sántha, P. Ferdinandy, Hypercholesterolemia increases myocardial oxidative and nitrosative stress thereby leading to cardiac dysfunction in apoB-100 transgenic mice, Cardiovasc. Res. 76 (2007) 100-109.

[29] M. Drigotas, A. Affolter, W.J. Mann, J. Brieger, Reactive oxygen species activation of MAPK pathway results in VEGF upregulation as an undesired irradiation response, J. Oral Pathol. Med. 42 (2013) 612-619.

[30] C. Salata, S.C. Ferreira-Machado, C.B. De Andrade, A.L. Mencalha, C.A. Mandarim-De-Lacerda, C.E. de Almeida, Apoptosis induction of cardiomyocytes and subsequent fibrosis after irradiation and neoadjuvant chemotherapy, Int. J. Radiat. Biol. 90 (2014) 284-290.

[31] M. Abdel-Wahab, A.V. Schally, G.F. Rick, L. Szalontay, L.N. Block, M. Jorda, O. Mahmoud, A. Markoe, Y.F. Shi, T. Reiner, M. Zarandi, R. Duncan, Antagonists of growth hormone releasing hormone (GHRH) given before whole body radiation lead to modulation of radiation response and organ-specific changes in the expression of angiogenesis, J. Radiat. Oncol. 1 (2012) 389-396. 